\title{
PERFORMANCE OF SILT PROTECTOR IN THREE DIMENSIONAL FLOWS
}

\author{
Dr. Dr. h.c. Rajesh P. Dubey ${ }^{1}$, Dr. Bitanjaya Das ${ }^{2}$, Dr. P.K. Mohanty ${ }^{3}$ \\ ${ }^{1}$ General Manager (P\&H), WAPCOS Limited, 76-C, Sector-18, Gurgaon-122015, India \\ ${ }^{2}$ Sr. Professor \& Dean, KIIT University, School of Civil Engg., Bhubaneswar-24, India \\ ${ }^{3}$ Professor, Marine Science Deptt., Berhmpur University, Berhampur-7, Odisha
}

rajeshpdubey@gmail.com

Keywords: silt curtain, turbidity, concentration, flux, advection and diffusion, settling.

\begin{abstract}
Performance of silt-curtain in three dimensional sea is investigated through a series of experiments. It is found that there are three mechanisms to reduce concentration and flux of turbidity generated by the construction work from flowing out of the construction site enclosed with silt curtains. The first is the temporal storage of turbidity and retardation of the flow of turbidity around the curtain. The second is the acceleration of dispassion of turbidity caused by the turbulence generated around the curtain that decreases the peak value of concentration of turbidity. The last one is the reduction of flow velocity in the enclosed area. As a result, the diffusion time increases and the amount of turbidity settled down in the enclosed region increases.

Taking these mechanisms into account a simple procedure to predict reduction of flow velocity and the flux of turbidity is proposed. The applicability of the proposed procedure is examined using experimental results.
\end{abstract}

\section{INTRODUCTION}

Generation of turbidity in the coastal region is unavoidable in the construction work of various kind of coastal structures. Turbidity caused by the dredging, sand damping for sand mat and so on often has fatal effects for fish habitation and ecosystem especially in the semi-enclosed sea. To prevent from dispersing and spreading out SS from the construction site, a silt curtain has been usually used.

Although some experimental studies have been carried out to, investigate the performance of siltcurtain in a two-dimensional wave tank (Kano et. at., 1987, Sawaragi et.al., 1968 and Oda et. al., 1990) and field (Furudoi, 1989), any investigation of the performance of silt curtain has not been done in three-dimensional sea. At present, there is not any definite guide line for the plane arrangement and expansion of silt curtain in the sea.

The aim of this study is to examine the performance of silt curtain through a three-dimensional model basin. The effects of siltcurtain stretched in the sea on reducing flow velocity in the enclosed region with the silt curtain and on decreasing flux of SS from flowing out of the enclosed region is investigated. A simple procedure to predict reduction of flow velocity and flux of SS is proposed. The applicability of the proposed procedure is examined by using experimental results.

\section{EXPERIMENTS ON THE PERFORMANCE OF SILT CURTAIN}

\subsection{Experimental setup and facility}

Experiments were carried out in the water basin of $\mathrm{S} \mathrm{m}$ wide, $12 \mathrm{~m}$ long and $0.6 \mathrm{~m}$ deep. Two types of silt curtain and their combination are examined. One is a "stand-up" type fixed on the bottom and stretched by the float at the top and the other is a 'hang-down" type from the float on the sea surface. The definition of variables together with the sketch of both type curtains are shown in Fig. 1. 


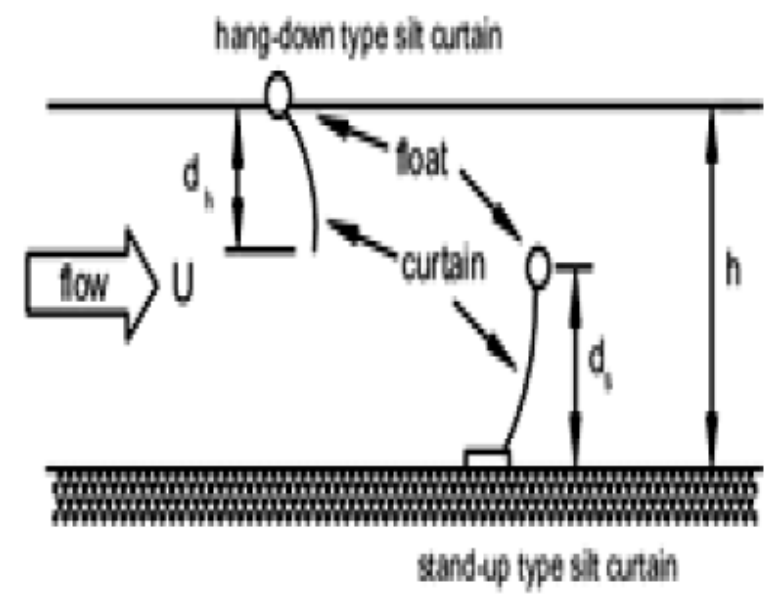

Fig. 1: Definition Sketch of Silt Curtain

Uniform flow of the mean velocity $10 \mathrm{~cm} / \mathrm{s}$ was generated by a flow generator as shown in Fig.2. Water depth was kept constant to be $20 \mathrm{~cm}$ through the experiments.

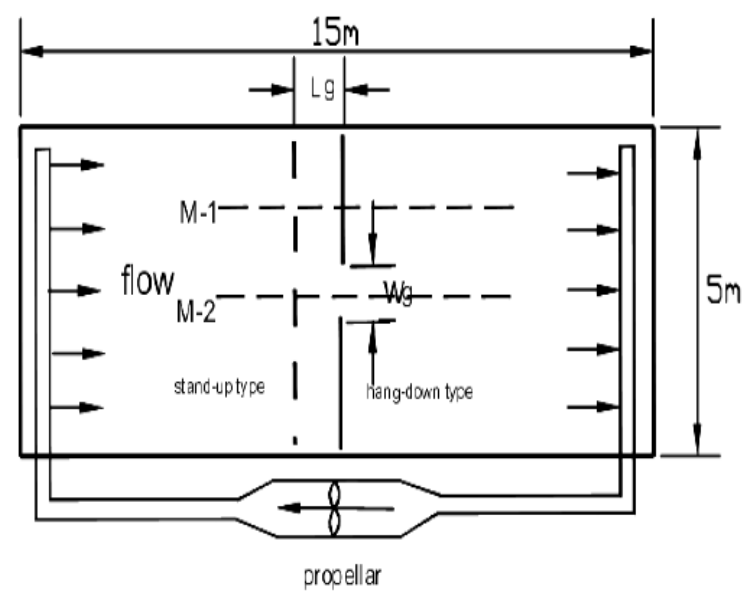

Fig. 2: Arrangement of Silt curtain in Experiment I

Performance of two types of plane arrangements basin. The effects of silt curtain stretched in the sea on reducing flow velocity in the enclosed region with the silt curtain and on decreasing flux of SS from flowing out of the enclosed region is experiment, hang-down type of the curtains were set behind the stand-up type curtain with the opening $\mathrm{Wg}=1.0 \mathrm{~m}$ as shown in Fig.2.

In the second experiment, a part of the water basin was enclosed with silt curtains as shown in Fig.3 (Experiment II). The length and the width of enclosed region Ls and Ws were set to be 4-6 in and $2 \mathrm{~m}$, respectively. In the case where the both stand-up and hand-down types curtains were expanded, the hang-down type curtain was set inside. The distance between them Lg was $0.5-1.0 \mathrm{~m}$.

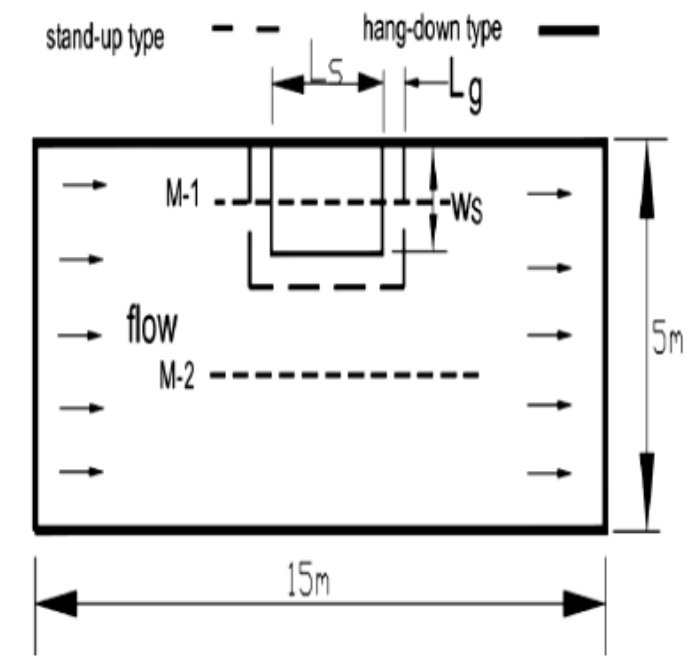

Fig. 3: Arrangement of Silt curtain in Experiment II 
The experimental conditions of the first and second experiments are summarized in Tables 1 and 2 . In the experiment 1 , a fundamental hydraulic function of silt curtain is examined. A practical performance of silt curtains is investigated in the Experiment II.

Table 1 (Experiment I)

\begin{tabular}{|c|c|c|c|c|}
\hline Case & $\begin{array}{c}\mathbf{d s} \\
(\mathbf{c m})\end{array}$ & $\begin{array}{c}\mathbf{d h} \\
(\mathbf{c m})\end{array}$ & $\begin{array}{c}\mathbf{L g} \\
(\mathbf{c m})\end{array}$ & $\begin{array}{c}\mathbf{L i} \\
\mathbf{( m )}\end{array}$ \\
\hline Et-0 & - & - & - & -2.5 \\
\hline Et-1 & 7 & - & - & -2.5 \\
\hline E1-2 & 10 & - & - & -2.5 \\
\hline E1-3 & 15 & - & - & -2.5 \\
\hline E1-4 & 7 & 5 & 50 & -2.5 \\
\hline E1-5 & 7 & 5 & 100 & -2.5 \\
\hline E1-6 & 15 & 7 & 50 & -2.5 \\
\hline E1-7 & 15 & 6 & 75 & -2.5 \\
\hline EI-8 & 15 & 5 & 100 & -2.5 \\
\hline
\end{tabular}

Table 2 (Experiment II)

\begin{tabular}{|c|c|c|c|c|c|c|}
\hline Case & $\begin{array}{c}\text { Ds } \\
\text { cm }\end{array}$ & $\begin{array}{c}\mathbf{d h} \\
\mathbf{c m}\end{array}$ & $\begin{array}{c}\mathbf{L s} \\
\mathbf{m}\end{array}$ & $\begin{array}{c}\mathbf{L g} \\
\mathbf{c m}\end{array}$ & $\begin{array}{c}\mathbf{W s} \\
\mathbf{m}\end{array}$ & $\begin{array}{c}\mathbf{L i} \\
\mathbf{m}\end{array}$ \\
\hline $\mathrm{E} 2-1$ & 7 & - & 4 & - & 1.5 & 1 \\
\hline $\mathrm{E} 2-2$ & 7 & - & 6 & - & 1.5 & 1 \\
\hline E2-3 & 7 & 5 & 4 & 50 & 1.5 & 1 \\
\hline E2-4 & 7 & 5 & 4 & 100 & 1.5 & 1 \\
\hline E2-5 & 7 & 5 & 6 & 50 & 1.5 & 1 \\
\hline E2-6 & 7 & 5 & 6 & 50 & 1.5 & 2 \\
\hline E2-7 & 7 & 5 & 6 & 50 & 1.5 & 3 \\
\hline E2-8 & 7 & 5 & 6 & 50 & 1.5 & 4 \\
\hline E2-9 & 5 & 7 & 4 & 50 & 1.5 & 1 \\
\hline E210 & 7 & 5 & 4 & 0 & 1.5 & 1 \\
\hline E2-11 & 7 & 5 & 6 & 50 & 1.5 & 1 \\
\hline E2-12 & 10 & - & 6 & - & 1.5 & 1 \\
\hline E2-13 & 10 & 5 & 6 & 50 & 1.5 & 1 \\
\hline
\end{tabular}




\begin{tabular}{|c|c|c|c|c|c|c|}
\hline Case & $\begin{array}{c}\text { Ds } \\
\text { cm }\end{array}$ & $\begin{array}{c}\text { dh } \\
\mathbf{c m}\end{array}$ & $\begin{array}{c}\text { Ls } \\
\mathbf{m}\end{array}$ & $\begin{array}{c}\mathbf{L g} \\
\mathbf{c m}\end{array}$ & $\begin{array}{c}\mathbf{W s} \\
\mathbf{m}\end{array}$ & $\begin{array}{c}\mathbf{L i} \\
\mathbf{m}\end{array}$ \\
\hline $\mathrm{E} 2-14$ & 10 & 5 & 6 & 50 & 1.5 & 2 \\
\hline $\mathrm{E} 2-15$ & 10 & 5 & 6 & 50 & 1.5 & 3 \\
\hline $\mathrm{E} 2-16$ & 10 & 5 & 6 & 50 & 1.5 & 4 \\
\hline $\mathrm{E} 2-17$ & 10 & - & 4 & - & 1.6 & 1 \\
\hline $\mathrm{E} 2-18$ & 7 & - & 4 & - & 1 & - \\
\hline $\mathrm{E} 2-19$ & 7 & - & 4 & - & 2 & - \\
\hline
\end{tabular}

By comparing results obtained from these experiments, we will investigate the following points at issues:

- effect of length of enclosure : E2.1, E2-2 \& E2-12,E2- 17

- effect of height of stand-up type : E2-1, E2-17 \& E2-2,E2-12

- effect of hang-down type curtain : E2-1,E2-3

- effect of distance between stand-up and hang-down curtain : E2-3,E2-4

- effect of opening of hang-down type curtain : E2-3, E2-11 (Gap of 50cm was made in a hangdown type silt curtain)

- effect of plain arrangement : E.2-3,E2-9

- effect of width of enclosure : E2-3,E2-18,E2-19 (only velocity was measured in F.2-18 and F.219)

\subsection{Experimental Procedure}

In the experiment I and II, flow velocity was measured at the point set along the line M-1 and M-2 at a distance of $25-50 \mathrm{~cm}$ by two three-element acoustic Doppler velocity meters. Velocity at 3 to 5 points of different depth was measured at one measuring point to determine the vertical profile of velocity.

In the both experiments, concentration of injected turbid water (solution of kaolin of the concentration of $8000 \mathrm{ppm}$ ) in the enclosed region was also measured. Turbid water of $600 \mathrm{~cm} 3$ was injected instantaneously at the point on the line M-1 and downstream side of the inner curtain as shown in Fig. 4. In the experiment 1, turbid water was injected $2 \mathrm{~m}$ upstream side of the stand-up type silt curtain. The distance between injection point and inner curtain was $\mathrm{Li}$ in the experiment 11 . The concentration of turbid water was measured along the line M-1 at the interval of $25-50 \mathrm{~cm}$ from the injection point by vertically distributed three optical turbidity meters at the distance of $7.5 \mathrm{~cm}$ from the bottom.



Fig. 4: Injection Point of turbid water 
The measured signals of velocity and concentration were digitized at time interval of $0.1 \mathrm{~s}$ and recorded in the personal computer. Mean values and fluctuation from the mean of the velocity and concentration were calculated.

\section{EXPERIMENTAL RESULTS AND DISCUSSIONS}

Here, velocity around silt curtain and effect of silt curtain on the spreading of turbidity are first examined based on the results of experiment 1 . Then the effect of enclosure on the reduction of flow velocity and settling of turbidity are discussed based on results of Experiment II.

\subsection{Velocity around silt curtain}

Figure 5 (a) and (b) show the flow pattern measured around a single stand-up type curtain of the height 15cin (for Case E1-3) and that around stand-up type curtain of the height of $15 \mathrm{~cm}$ and hangdown type curtain of the height $5 \mathrm{~cm}$ set a part at the distance of 50em ( for Case F.1 -6).

Both stand-up and hang-down type curtains bend before the current and their height decrease. From Fig.5, it is found that flow behind the stand-up type curtain is disturbed in the region within $100 \mathrm{~cm}$ downstream from the curtain. The length of the disturbed region behind the stand-up type curtain is about 6 to 8 times of the height of curtain. When the hang-down type curtain was set behind the stand-up type curtain, the length of disturbed region decreases a little as shown in Fig.5(b).

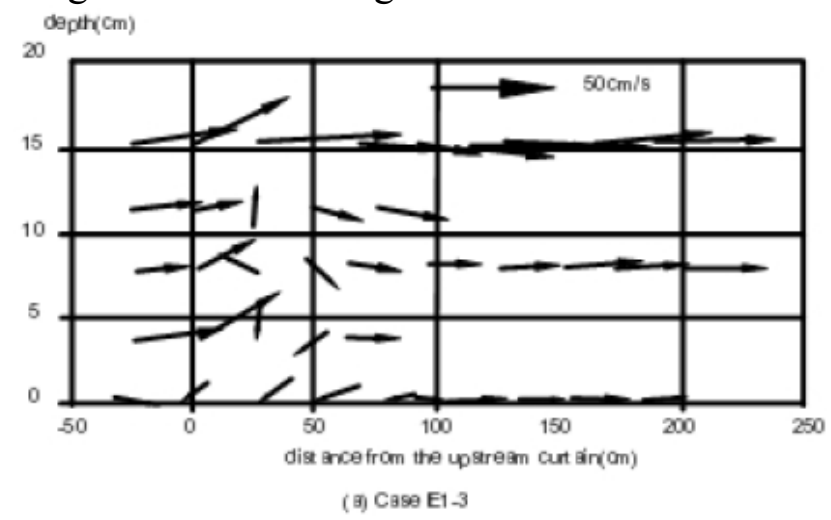

Fig. 5(a): Flow Pattern around silt curtain

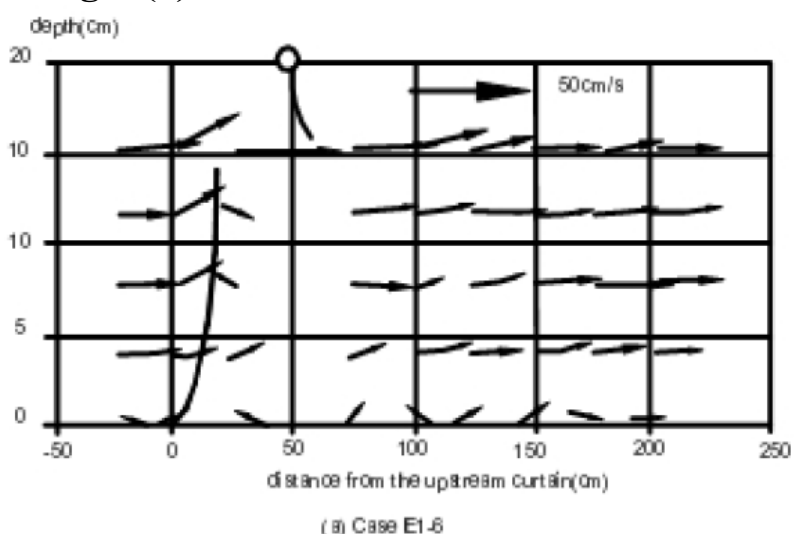

Fig. 5(b): Flow Pattern around silt curtain

\subsection{Effect of Silt Curtain on the spreading of turbidity}

Figure 6 shows the time history of measured concentration at the bottom along the line M-1 in the case of E1-0 (without curtain, Fig.6(a)) and E1-8 (Fig.6(b)).

In the case of El-0 without curtain, the time variation of measured concentration even $425 \mathrm{~cm}$ downward from the injection point has sharp peak. In the case of El-8, the stand-up type and hangdown type silt curtain were set $2 \mathrm{~m}$ and $3 \mathrm{~m}$ downstream side of the injection point. In the up- stream side of the curtain, the time variation of measured concentration is of the same profile as the case without the curtain shown in Fig.6(a). While in the region behind the curtain, the measured time variation of concentration becomes flat. 
From these results together with the observation of the experiment, the effect of silt curtain on flow and spreading of injected turbid water are summarized as follows:

Injected turbidity diffuse and its part settle in the process of advection by the flow smoothly and continuously without a silt curtain. If there is the silt curtain in the process of advection, some part of the flow containing turbidity pile up in front of the curtain and advection of the turbidity delays when compared with the advection of the turbidity without curtain. When the flow passes the top of curtain, a strong turbulence is generated by flow separation and this causes intense diffusion of turbidity. Some part of the turbidity settles in the dead water region behind the curtain. As a result, peak-cut of the concentration occurs. These processes are shown in Fig.7.

\subsection{Decrease in velocity in the enclosed region}

The current velocity decreases in the enclosed region with a silt curtain. Figure 8 illustrates the comparison of the measured mean current velocity $U$ in the enclosed region normalized by the measured velocity lie for Case E1-0 without curtain.

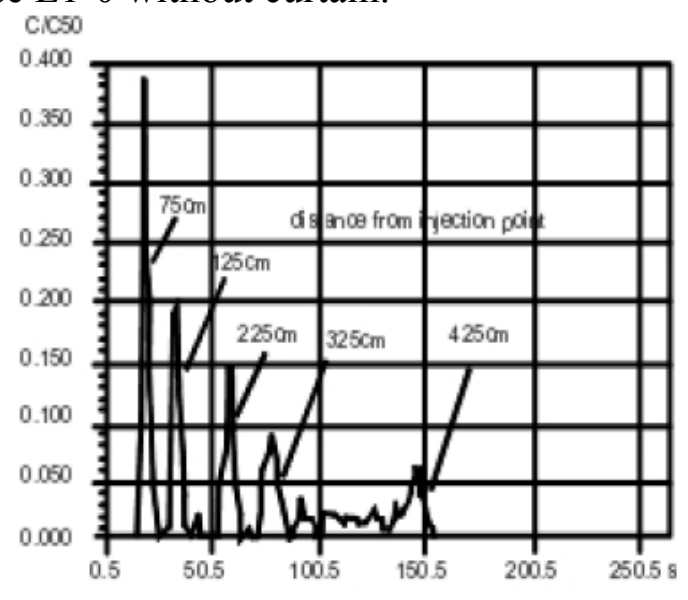

(8) $\mathrm{C} 998 \mathrm{E} 10$

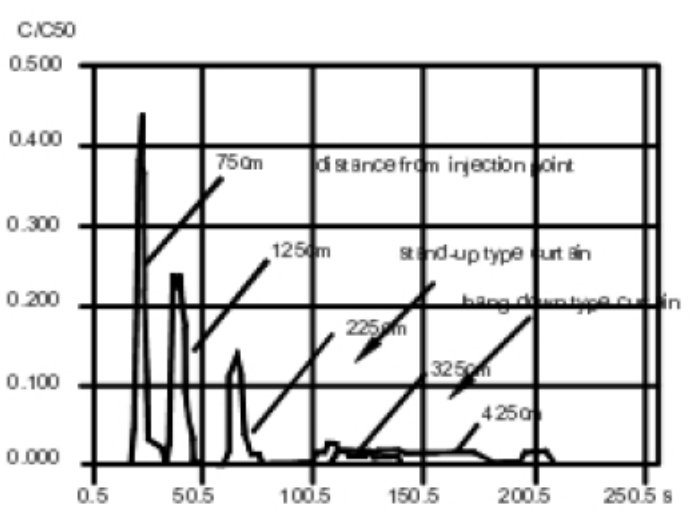

(b) $\mathrm{C}$ ase $\mathrm{E} 1.8$

Fig. 6: Time variation of measured concentration in the downstream direction
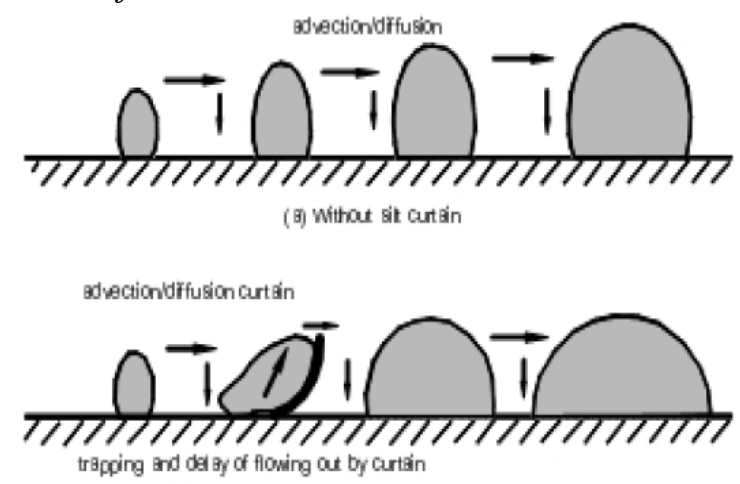

(b) with silt curt in

Fig. 7: Schematic description of the effect of silt curtain on the flow and spreading of turbidity 
The value of velocity in the enclosed region decreases $50 \%$ when compared with the case of no curtain even in the case where the stand-up type silt curtain was set independently (E2-1,E2-2,E212). When the stand- height $5 \mathrm{~cm}$ are set at the same place $(3-2.10)$, the value of velocity decreases to almost $1 / 4$.

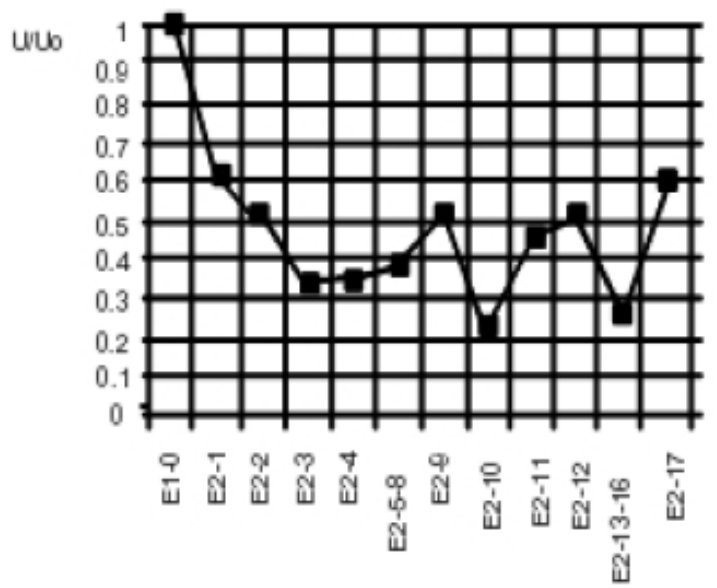

Fig. 8: Decrease in the mean flow velocity in the enclosed region

The decrease in velocity in the enclosed region causes the prolongation of advection time of injected turbidity and increase the settling volume of turbidity. Consequently, the concentration and total flux flowing out of the enclosed region decrease.

By comparing each case shown in Fig. 8 , the effect of silt curtain .on the reduction of flow velocity are summarized as follows:

- when the length of the enclosed region becomes long, U/Uo decreases a little (E2 - 1 vs. E2 - 2 and E2 - 17 vs. 112 - 12),

- height of stand-up type silt curtain has little influence on U,fUo within the range of ds/D is less than $1 / 2$ where D is the total depth (E2-1 vs. F.2-17 and E2-2 vs. E2-12),

- when hang-down type silt curtain is set outside of a stand-up type curtain, U/Uo decreases significantly (L'2-1 vs. E2-3 etc.),

- hang-down type silt curtain set inside of the stand-up type curtain has little influence on the decrease in flow velocity (E2-3 vs. E2-9),

Figures 9 and 10 show the comparison of the maximum concentration and total flux of turbidity measured outside of the enclosed region. In those figures, there was no silt curtain for Case 131-0 and $\mathrm{Cm} 4.5$ and $\mathrm{Cm} 5.5$ indicate the depth averaged maximum concentration measured at $4.5 \mathrm{~m}$ and $5.5 \mathrm{~m}$ downstream side of the injection point. The total flux of turbidity was calculated from the measured velocity and concentration of turbidity at $4.5 \mathrm{~m}$ and $5.5 \mathrm{~m}$ downstream side from the injection point.

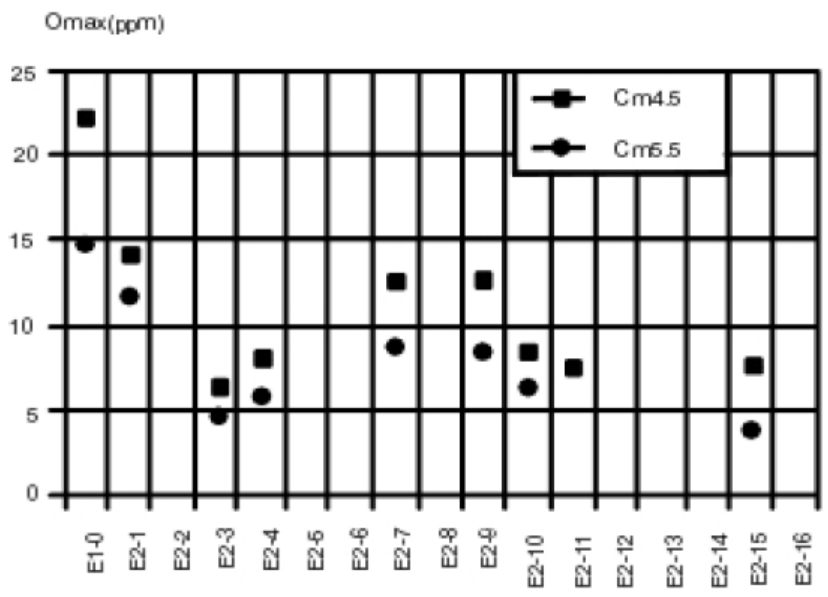

Fig. 9: Comparison of the maximum concentration 
From Fig.9, it is found that the maximum concentration decreased $60-80 \%$ of the maximum concentration measured in the case without curtain (E1-0) when the stand-up type silt curtain was set alone (E2-1). In the case where both stand-up and hang-down types curtains were set side by side, the maximum concentration decreases to $25-50 \%$ depending on the plane arrangement when compared with the case of no silt curtain. As a rule, the maximum concentration decreases as the flow velocity in the enclosed region decreases.

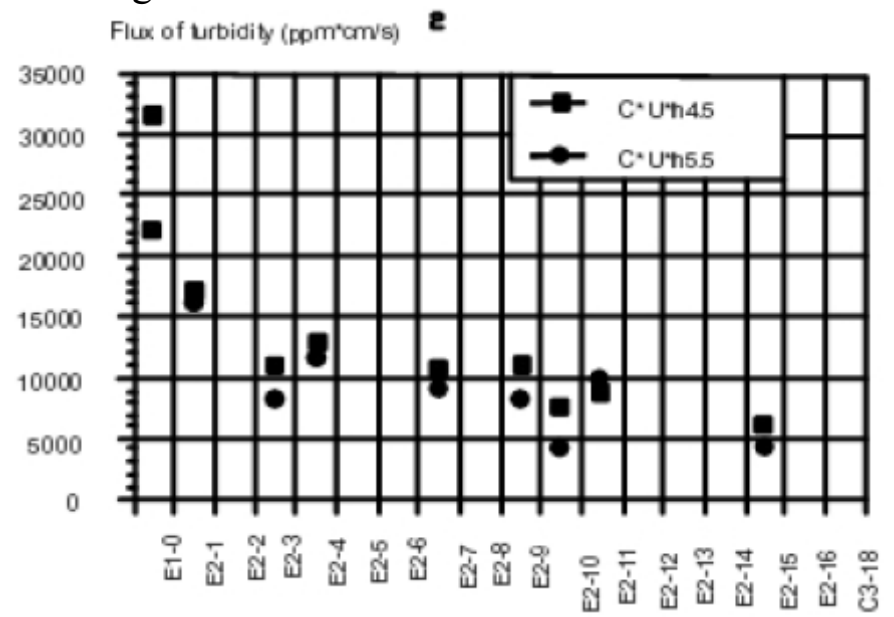

Fig. 10: Comparison of turbid flux

Since the flux of turbidity is calculated as a product of the velocity and concentration, the decrease in the maximum turbidity flux decreases largely as can be seen in Fig.10. When the height of the stand-up type silt curtain is $7 \mathrm{~cm}$, the maximum decrease in the flux takes place in the case E210.Figure 11 illustrates the relation between the mean flow velocity in the enclosed region and the flux flowing out of the enclosed region. Fo and Uo are the flux and velocity in the case without curtains. As can be seen from Fig.11, the flux flowing out of the enclosed region F/Fo decreases linearly with the decrease in the mean velocity in the enclosed region U/Uo.

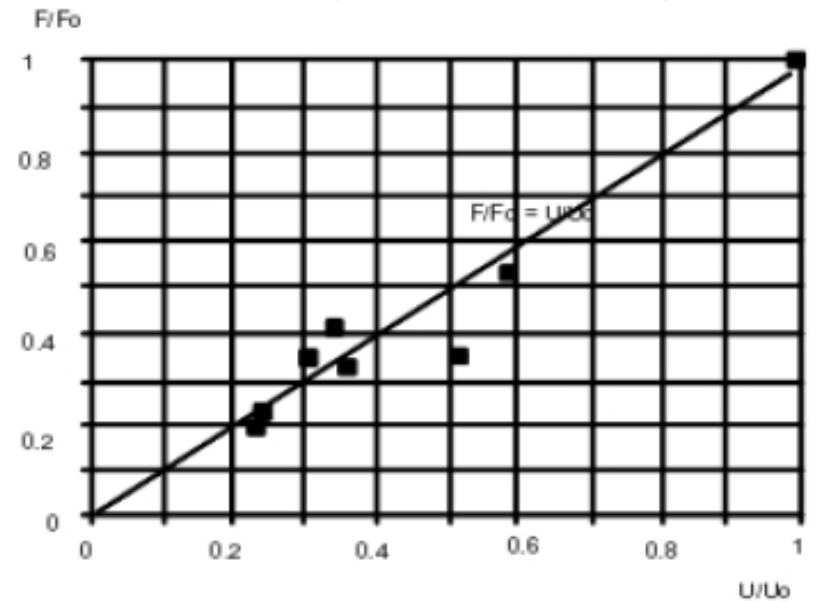

Fig. 11: Relation between the decrease of mean velocity and turbid flux

From these results, the amount of turbidity settling down in the enclosed region seems to be estimated provided that we can predict the flow velocity in the enclosed region and the information of the source of turbidity.

\section{A SIMPLE MODEL FOR ESTIMATING FLOW VELOCITY AND FLUX OF TURBIDITY FLOWING OUT OF ENCLOSED REGION}

\subsection{Velocity in the enclosed region}

The depth and time averaged mass and momentum flux conservation equations are solved to evaluate the velocity in the enclosed direction of mean flow and perpendicular to the main flow on 
the still water surface and $\mathrm{z}$-axis is upward from the still water surface, the equations to be solved are expressed as follows:

$$
\begin{aligned}
& \frac{\partial}{\partial \mathrm{t}}\left\{\mathrm{p}(\mathrm{h}+\bar{\eta}\}+\frac{\partial}{\partial \mathrm{x}}\{\mathrm{pU}(\mathrm{h}+\bar{\eta})\}+\frac{\partial}{\partial \mathrm{y}}\{\mathrm{pV}(\mathrm{h}+\bar{\eta})\}=0\right. \\
& \frac{\partial}{\partial \mathrm{t}}\left\{\mathrm{pU}(\mathrm{h}+\bar{\eta}\}+\frac{\partial}{\partial \mathrm{x}}\left\{\mathrm{pU}^{2}(\mathrm{~h}+\bar{\eta})\right\}+\frac{\partial}{\partial \mathrm{y}}\{\mathrm{pUV}(\mathrm{h}+\bar{\eta})\}=-\mathrm{pg}(\mathrm{h}+\bar{\eta}) \frac{\partial \bar{\eta}}{\partial \mathrm{x}}+\frac{\partial}{\partial \mathrm{x}}\left(\mathrm{k}_{\mathrm{x}} \frac{\partial \mathrm{U}}{\partial \mathrm{x}}\right)+\right. \\
& \frac{\partial}{\partial \mathrm{y}}\left(\mathrm{k}_{\mathrm{y}} \frac{\partial \mathrm{U}}{\partial \mathrm{y}}\right)-\tau_{\mathrm{x}} \\
& \frac{\partial}{\partial \mathrm{t}}\left\{\mathrm{pV}(\mathrm{h}+\bar{\eta}\} \frac{\partial}{\partial \mathrm{x}}\{\mathrm{pUV}(\mathrm{h}+\bar{\eta})\}+\frac{\partial}{\partial \mathrm{y}}\left\{\mathrm{pV}^{2}(\mathrm{~h}+\bar{\eta})\right\}=-\mathrm{pg}(\mathrm{h}+\bar{\eta}) \frac{\partial \bar{\eta}}{\partial \mathrm{x}}\right. \\
& \quad+\frac{\partial}{\partial \mathrm{x}}\left(\mathrm{k}_{\mathrm{x}} \frac{\partial \mathrm{U}}{\partial \mathrm{x}}\right)+\frac{\partial}{\partial \mathrm{y}}\left(\mathrm{k}_{\mathrm{y}} \frac{\partial \mathrm{U}}{\partial \mathrm{y}}\right)-\tau_{\mathrm{y}}
\end{aligned}
$$

Where $\mathrm{U}, \mathrm{V}$ are the depth and time averaged velocity in $\mathrm{x}$ - and $\mathrm{y}$-directions, $\mathrm{h}$ is the depth in still water, $\mathrm{h}$ is the surface displacement, $\mathrm{p}$ is the density of fluid, $\mathrm{g}$ is the acceleration of gravity, $\mathrm{k}$ and $\mathrm{k}$ are the coefficients of kinematic eddy viscosity and c, and $r$. are the time averaged bottom shear stresses in $\mathrm{x}$ - and $\mathrm{y}$ - directions. The time averaged bottom shear stresses are evaluated by the following empirical relations using a friction factor $\mathrm{f}$.

$$
\tau=\operatorname{pf} \sqrt{\mathrm{U}^{2}+\mathrm{V}^{2} \frac{\mathrm{U}}{2}, \tau_{\mathrm{x}}=\mathrm{pf} \sqrt{\mathrm{U}^{2}+\mathrm{V}^{2} \frac{\mathrm{V}}{2}}}
$$

An expression for the kinematic eddy viscosity by longuet-Higgins (970) is applied tentatively.

These equations are transformed into finite difference equations at the grid point of $\Delta x=\Delta y=\operatorname{Sent}$ and are solved by a so-called $\mathrm{ADl}$ method at time interval $\Delta \mathrm{t}=(0.1 \mathrm{~s})$. The effect of silt curtains are taken into account by reducing a water depth of the grid.

Figure 12 shows the comparison of calculated and measured mean current velocities in the enclosed region of five cases.

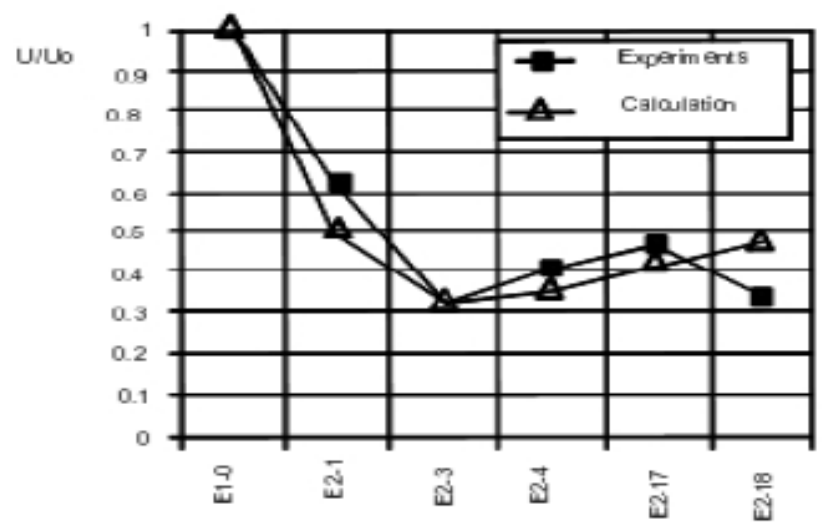

Fig. 12: Comparison of measured and calculated mean current velocity in the enclosed region

Flow velocity in the enclosed region can be roughly predicted fairly well by the present method regardless of the arrangement and dimension of silt curtains.

\subsection{Flux of turbidity}

To evaluate the flux of turbidity, the concentration of turbidity is first calculated by using an analytical solution of the concentration of instantaneously injected point source. In the coordinate system shown in Fig.13, the concentration of the material instantaneously injected at the origin of the coordinate $(0.0)$ is expressed by

$$
c(x, y, z, t)=\left(\frac{Q}{4 \pi t^{\frac{3}{2}}}\right)\left(\frac{1}{k_{x} k_{y} k_{z} \frac{3}{2}}\right) \quad \exp \left[-\frac{(x-u t)^{2}}{4 k_{x} t}-\frac{y^{2}}{4 k_{y} t}-\frac{\left(z+w_{f} t\right)^{2}}{4 k_{x} t}\right]
$$


where $\mathrm{Q}$ is the total amount of the material,wr is the settling velocity and $\mathrm{Kx}, \mathrm{Ky}$, and $\mathrm{Kz}$, are the diffusion coefficients in $\mathrm{x}-$, $\mathrm{y}$ - and $\mathrm{z}$-directions.

The center of the material moves along the line of $\mathrm{z}=-(\mathrm{wr} / \mathrm{U}) \mathrm{x}$ as shown in Fig.13.

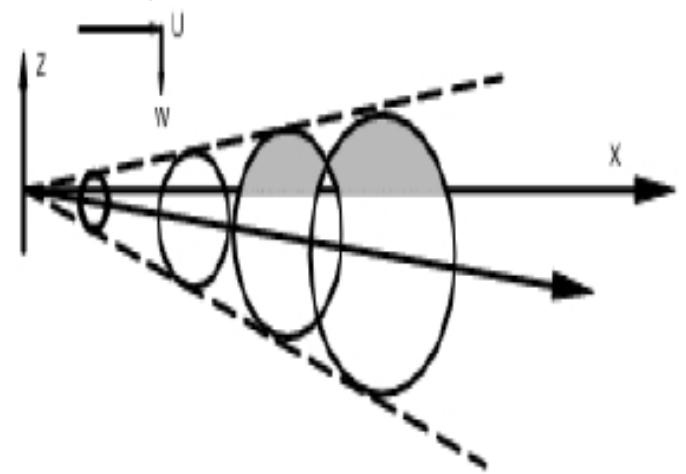

Fig. 13: Definition Sketch of the Model

If we assume that the concentration of the material under the region of $x<=0$ settle on the bottom, then the flux of advecting and diffusing material is calculated by the product of the following integration.

$$
\mathrm{F}(\mathrm{x}, \mathrm{y}, \mathrm{t})=\int_{0}^{\mathrm{h}} \mathrm{c}(\mathrm{x}, \mathrm{y}, \mathrm{z}, \mathrm{t}) \mathrm{Udz}
$$

Finally, the total flux of a arbitrary point along the center line of the injection point $y=0$ is calculated by integrating Eq.(6) in the region of

$$
\mathrm{F}(\mathrm{x}, 0)=\int_{0}^{\infty} \int_{0}^{\mathrm{h}} \mathrm{c}(\mathrm{x}, 0, \mathrm{z}, \mathrm{t}) \mathrm{Udzdt}
$$

Figures 14 and 15 show the comparison of measured and calculated if uses of injected kaolin in the case of E1-0 (without curtain) and E2-10. The value of $U$ in $\operatorname{Eq}(7)$ in the case of El-0 is 5.Occm. While the value of $U$ in the case of E2-10 is $1.2 \mathrm{~cm} / \mathrm{s}$.

The settling velocity wf of turbidity in a still water is determined to be $0.067 \mathrm{cmis}$ by the settling tests. The diffusion coefficients $\mathrm{Kx}, \mathrm{Ky}$ and $\mathrm{Kz}$, in Eq.(7) are determined to be $2 . \mathrm{Ocm} 2 / \mathrm{s}$ that can reproduce measured flux in the case of El-0.

In the case where there is no curtain, measured and calculated fluxes coincide fairly well. Although the calculated flux in the region of $15-2.0 \mathrm{~m}$ downstream from the injection point underestimates the measured value a little, the agreement between measured and calculated fluxes is not so bad for the case where the stand-up type and hang-down type curtains are constructed at the same place.

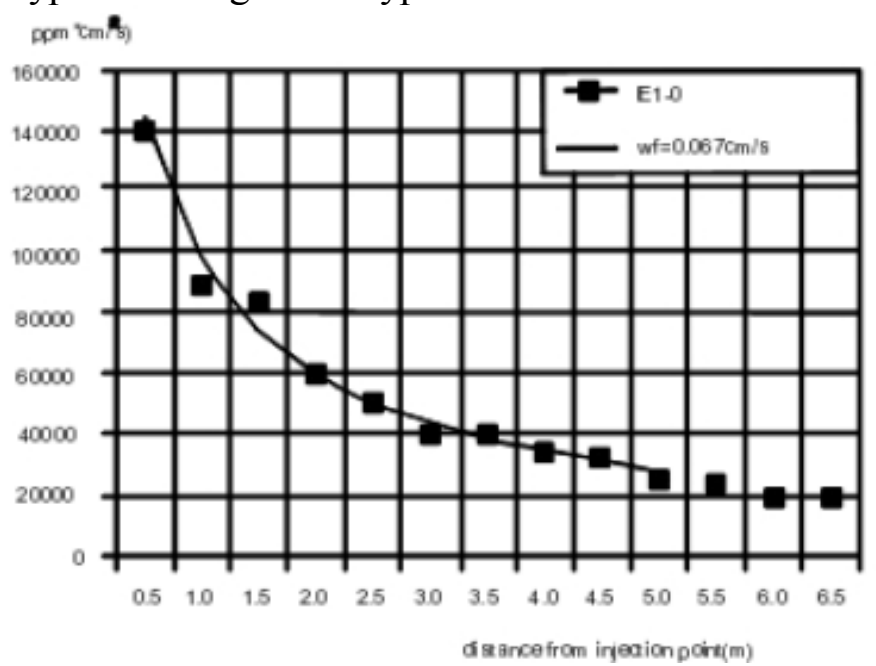

Fig. 14: Comparison of calculated and measured turbidity flux (Case E1-0) 


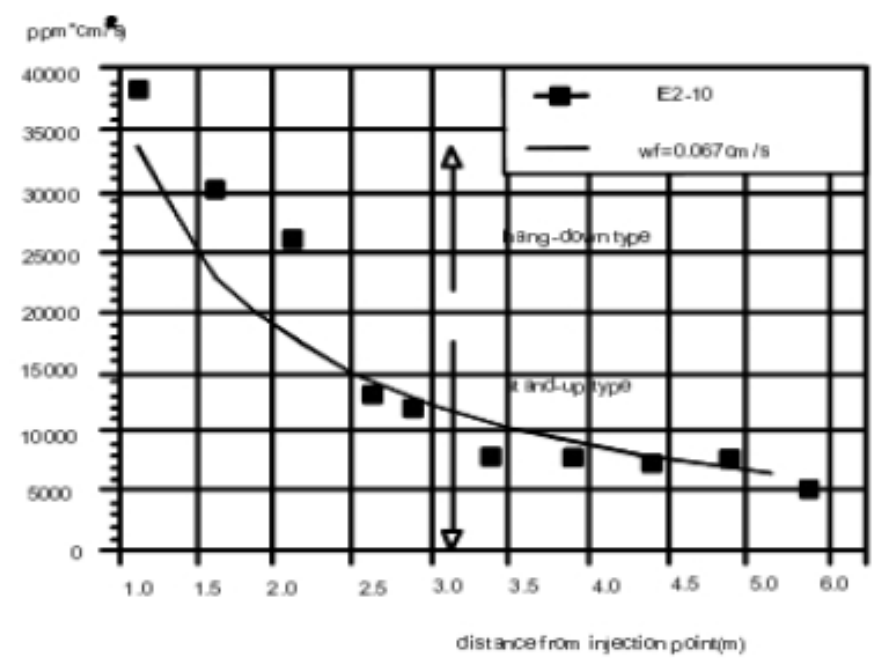

Fig. 15: Comparison of calculated and measured turbidity flux (Case E2-10)

\section{CONCLUSIONS}

Performance of silt curtain is investigated through experiments. The effect of the silt curtain on flow and dispersion of turbidity is first investigated in the water basin to know the three dimensional performance of silt curtains.

It is found that there are three mechanisms to reduce concentration, and flux of turbidity generated by the construction work from flowing out of the construction site enclosed with silt curtains.

The first is the temporal storage of turbidity and the retardation of the flow of turbidity around the curtain. The second is the acceleration of dispassion of turbidity caused by the turbulence generated around the curtain. The last one is the reduction of flow velocity in the enclosed area.

As a result, the diffusion time increases and the amount of turbidity settled down in the enclosed region increases. The last one is essentially the most effective to decrease turbidity flowing out of the enclosed region with the silt curtain. The rate of decrease of turbidity flux deeply depends on the decrease in the velocity in the enclosed region with silt curtains.

It is also found that the flow pattern around in the enclosed region with silt curtains can be predicted by solving depth and time averaged shallow water equations numerically where the effect of silt curtain is taking into account by reducing water depth at the curtain. The reduction of concentration and flux generated in the enclosed region is also reproduced by applying an analytical solution of the three dimensional turbulent diffusion equation. Acknowledgment is heartily expressed to authors mentioned under references.

\section{REFERENCES}

[1] Furudoi, M. (1989): Study on behavior of turbidity generated by construction works in the sea, Doctor Thesis, Osaka University.

[2] Kano, T., Y. Ilonjo and H. Kawamoto (1987): Studies on silt protecting effect of double installed half depth silt protector sheet, Proc.Civil Engineering in the Ocean, Vol.3, pp.209-214.

[3] Longuet-Hoggins, M. S. (1970): Longshore current generated by obliquely incident sea waves, 1 and 2, JGR., Vo1.75, pp.6778-6789 and pp. 6790-6801.

[4] Oda, K., T. Shigematsu, Y. Hamazaki and 11. Yamase (1990): Study on the effect of silt curtain, Proc..Japanese Conf. on Coastal Engineering, Vol.37, pp.843-847.

[5] Sawaragi, "G, S. Aoki and A. Yasui (1988): Experimental study on fluid force on silt curtain of stand-up type, Proc. Civil Engineering in the Ocean, Vol.4, pp.313-318.

[6] Yusai, Akio, Taiyo Kogyo Co., Japan; Deguchi, Ichiro and Ono, Masarobu: experimental study. 